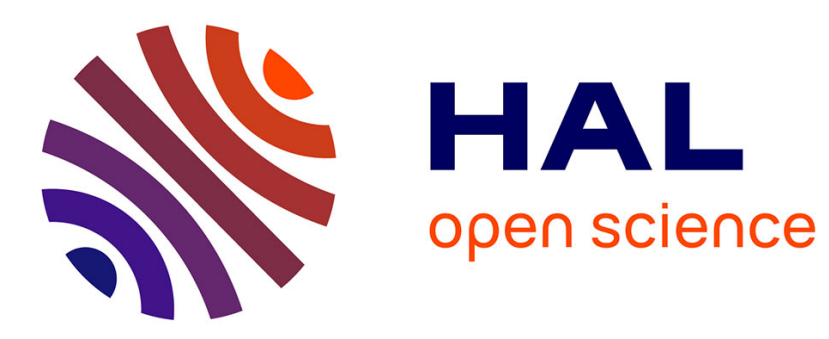

\title{
Machining dispersions based procedures for computer aided process plan simulation
}

Said Hamou, Abdelmadjid Cheikh, Jean-Marc Linares, Ali Benamar

\section{To cite this version:}

Said Hamou, Abdelmadjid Cheikh, Jean-Marc Linares, Ali Benamar. Machining dispersions based procedures for computer aided process plan simulation. International Journal of Computer Integrated Manufacturing, 2004, 17 (2), pp.141 - 150. 10.1080/0951192031000104464 . hal-01410125

\section{HAL Id: hal-01410125 \\ https://hal-amu.archives-ouvertes.fr/hal-01410125}

Submitted on 6 Dec 2016

HAL is a multi-disciplinary open access archive for the deposit and dissemination of scientific research documents, whether they are published or not. The documents may come from teaching and research institutions in France or abroad, or from public or private research centers.
L'archive ouverte pluridisciplinaire HAL, est destinée au dépôt et à la diffusion de documents scientifiques de niveau recherche, publiés ou non, émanant des établissements d'enseignement et de recherche français ou étrangers, des laboratoires publics ou privés. 


\title{
Machining dispersions based procedures for computer aided process plan simulation
}

\author{
SAID HAMOU and ABDELMADJID CHEIKHJEAN MARC LINARESALI BENAMAR
}

\begin{abstract}
Among the whole manufacturing cycle of a product, a sequence of manufacturing stages needs to be optimized using the increasingly available computing resources. Computer aided process planning is seen as the missing link between CAD and CAM, which relates to the translation of design tolerances into manufacturing tolerances to be executed in the shop - oor. A computerized module for process plan simulation, taking into account the manufacturing dispersions, has been developed. The process plan simulation program, which consists of three procedures, uses a combination of the minimal transfer method and a modi®ed form of the dispersions method. The ${ }^{\circledR}$ rst procedure performs a veri®cation of the feasibility of the project's process plans through tolerance transfer. The second procedure performs an optimization of the tolerance distribution using the process capability data. The third procedure computes the manufacturing dimensions, which ensure the quality of the components and products. The simulation module has been validated on complex problems and shows that it gives good results in a short time. The manual work requires several days to solving this manufacturing problem.
\end{abstract}

\section{Introduction}

The last two decades have seen an enormous increase in the use of computers in industrial engineering activities. In fact, nowadays, computer resources can be exploited to speed-up and improve the accuracy of design, manufacture and assembly activities. Several stages of the manufacturing process of a product are therefore increasingly bene $\otimes_{t i n g}$, to different degrees, from this substantial computing power. However, despite the computerization of design

Authors: Said Hamou and Abdelmadjid Cheikh, Laboratoire d'Automatique de Tlemcen, Dêpartement de Mêcanique, Facultề des Sciences de l'Ingênieur, Universitề Abou Bekr Belkaid, Tlemcen, B.P.230, Tlemcen 13000, Algeria. E-mail: acheikh@mai.univ-tlemcen.dz. Jean Marc Linares, Laboratoire EASM2, Dêpartement Gênie mêcanique et Productique, Institut Universitaire de Technologie, Universitể de la Mêditerranêe, France. Ali Benamar, Dêpartement de Mêcanique, ENSET Oran, B.P. 1523, 31000, Algeria.
(CAD) and manufacturing (CAM) it is extremely dif®cult to ensure a communication between the two activities when several types of technological data are used, especially tolerances (Cheikh 1997). Computer aided process planning (CAPP) is sometimes seen as the missing link between CAD and CAM (Weill 1988, Halevi and Weill 1995). In fact CAPP can provide direct links to the design activity in terms of geometric de ${ }^{\circledR}$ nition and component attributes, such as functional dimensions and tolerances (Graves and Biscard 1999). At the same time it can create links towards the control and inspection activities of manufacture. Therefore, special attention is directed towards the analysis of manufacturing dimensions and tolerances, which ensure the quality of the product as dictated by the functional requirements. The process plan simulation, sometimes called manufacturing dimensions planning (see $®$ gure 1 ), is a very dif $\AA$ cult step to computerize in process planning. In fact the technical literature (Hamou 1998) shows that this procedure has been used manually and, in some cases, partially automated. Bourdet (1975) ®rst laid down the basis for process plan simulation based on the manufacturing process capabilities in terms of minimal machining dispersions. The simulation was performed manually as a tolerance transfer and optimization from design to manufacture. Taking into account the minimal machining dispersions, Duret (1981) proposed the minimal transfer method, which automates the verißcation of the feasibility of a process plan. Fainguelernt et al. (1986) presented a computer program that automates the tolerance optimization procedure, starting from a data matrix of minimal reference dispersions. However, the program lacks any automated procedure for the feasibility check of the process plan and the solution to impossible tolerance transfer conditions prior to the optimization. This paper presents a programmed module that completely automates the process plan simulation of a manufacturing pre-project. The mini- 

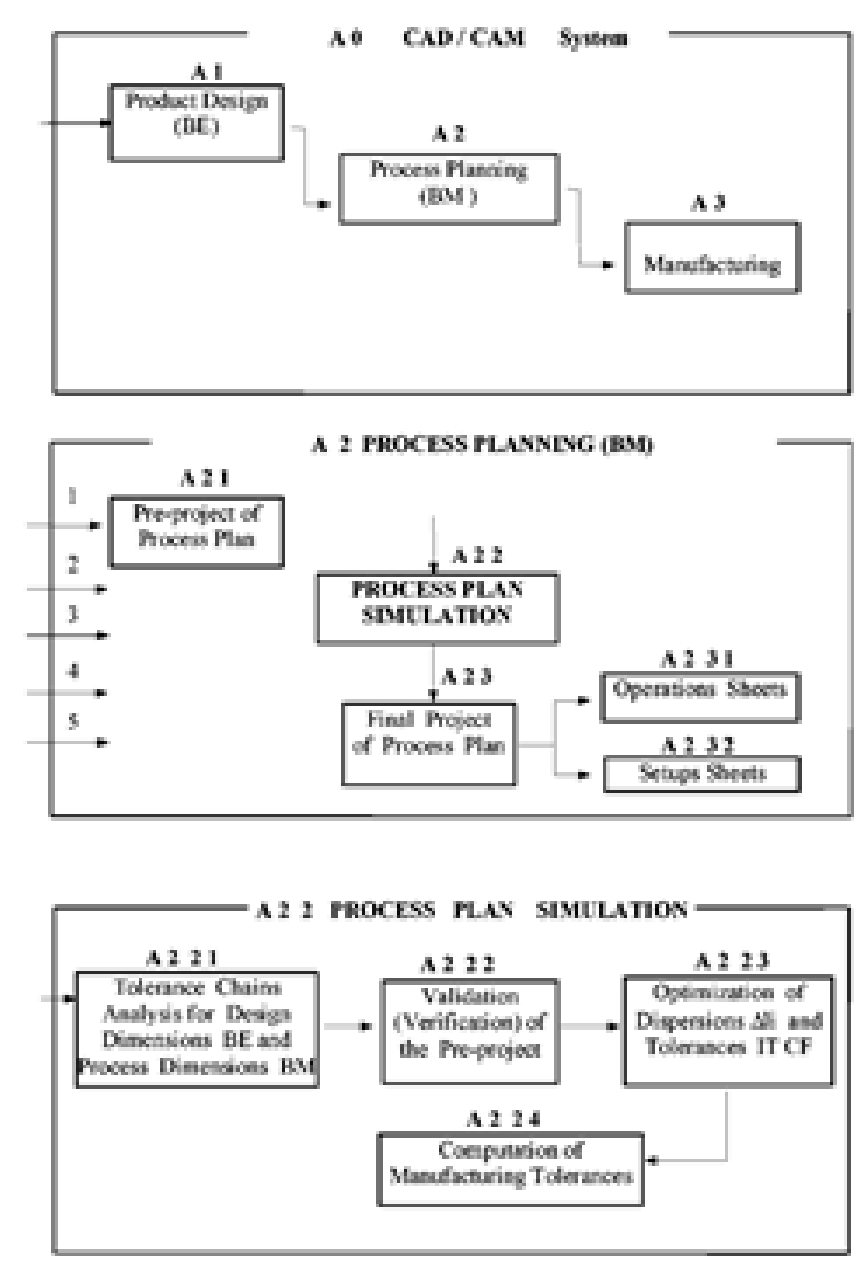

Figure 1. Process plan simulation module.

mal transfer method and the machining dispersions method are combined in order to automate the process plan feasibility veri®cation. In addition, the paper proposes a modi®ed and programmable methodology, which integrates the veri®cation and optimization in the same procedure, starting with a data matrix of unknown dispersions instead of a data matrix of minimal reference dispersions. A comparison between the two methodologies is given in this paper.

\section{Modelling of the process plan simulation}

In order to automate completely the process plan simulation, a programmable methodology is proposed as a combination of the machining dispersions method introduced by Bourdet (1975) and the minimal transfer method introduced by Duret (1981). On one hand, these two methods are rebuilt so that they can solve any tolerance transfer problem. On the other hand, the methodology is built so that it can calculate an optimal distribution of the machining dispersions (capabilities) and @nally to compute optimal manufacturing dimensions and tolerances. The @nal simulation module is designed in the form of three chronological procedures. The $囚$ rst procedure performs a veri®cation of the manufacturing pre-project (A222 in ®gure 1). The second procedure consists of the optimization of dispersions (A223 in @gure 1). The third procedure computes the ${ }^{\circledR}$ nal optimized manufacturing dimensions (A224 in ®gure 1).

\subsection{Fundamental dispersions model}

If a machine is set up to execute a given operation in quantity production there are inevitably various uncontrollable stochastic factors that affect the ${ }^{\circledR n}$ nal size for the dimension I of a machined component. The measured sizes usually give a variation (scattering) DI called machining dispersion. It is the difference between the largest size $I_{n}$ and the lowest size $I_{1}$ for a given batch as follows:

$$
\mathrm{DI}<\mathrm{I}_{\mathrm{n}} \ddot{\mathrm{Y}} \mathrm{I}_{1} \text { : }
$$

These different dispersions will affect the process capability and consequently the manufacturing dimensions. They are usually due to localization and ®xture errors, machine rigidity and tool rigidity. The objective of the simulation is to verify the feasibility of the design speci®cations (dimensions $\mathrm{BE}$ ) and the manufacturing conditions (dimensions BM) using a dispersions based fundamental model introduced by Bourdet (1975). In this model, for each phase in the process plan, the total dispersions $\mathrm{Dl}_{\mathrm{i}}$ for a machined surface or $\mathrm{Dl}_{\mathrm{i}}$ for a positioning surface represents the positions occupied by surface $i$ in relation to the machine referential system.

\subsection{Procedure for the verißcation of the pre-project based on minimal dispersions}

The veri®cation of the process plan pre-project is carried out by checking the feasibility of the process plan with regards to the capabilities of the available manufacturing processes in the workshop. This condition is ful@lled when the manufacturing means can produce the design set dimensions imposed by the design of®ce. In technical terms, this condition is satis@ed when the tolerance interval (IT) of the design dimension $B E$ is greater than or equals the manufacturing tolerance due to the summation of all dispersions $\mathrm{Dl}_{\mathrm{i}}$ and is given as: 


$$
\text { IT -dimension BEf5 }{ }^{\mathbf{X}} \mathrm{Dl}_{\mathrm{i}} \text { : }
$$

In order to automate the task of the veri®cation using the minimal transfer method in conjunction with equation (2), the manufacturing pre-project of a sample, an example of which is shown in ®gure 2 for a mechanical part, is written in a matrix format of $\mathrm{I}_{p}$ lines and $\mathrm{I}_{\mathrm{s}}$ columns. Figure 3 highlights a sample verißcation sequence for design dimension $\mathrm{BE}=16+0.6$. In this @gure, $\mathrm{I}_{\mathrm{s}}$ represents a surface varying between 1 to 8 and $I_{p}$ represents a phase varying between 1 to 5 . The element $A\left(I_{p}, I_{s}\right)$ of the initial matrix contains a dispersion value only when surface $I_{s}$ intervenes in phase $I_{p}$ as a machined surface (DI) or as a positioning surface (Dl', Dl", Dl"', ..) in an subsequent phase. Otherwise the value is set to zero. The manufacturing tolerance interval given by $\mathrm{SDl}_{i}$ is computed using the method of minimal transfer and is then compared to IT, the tolerance interval of the design dimension (BE). This method is explained in the sample example of ®gure 3 and the - owchart steps of ®gure 4. The veri®cation procedure is carried out for each design dimension (BE) by successive elimination of the dispersions from single element columns and lines, except for columns whose surfaces are limits to a design dimension (BE). In fact, on one hand, columns (surfaces) with one dispersion $\mathrm{Dl}$ are eliminated because they are not taking part in the localization of a surface. On the other hand, lines (phases) having

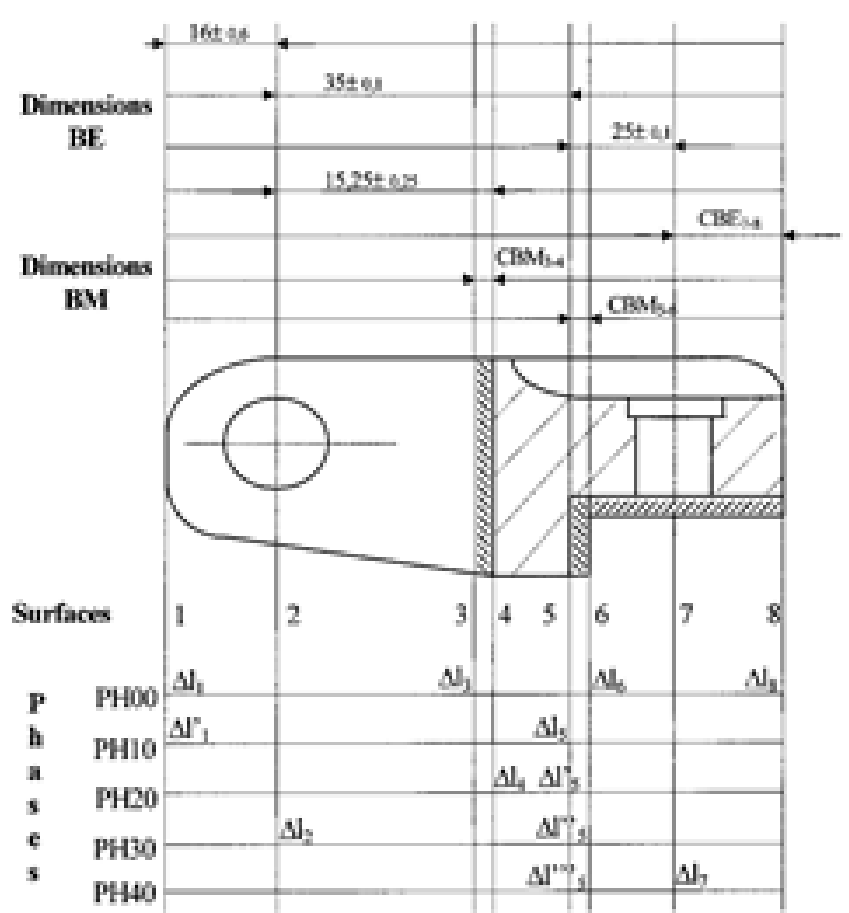

Figure 2. Sample example of a mechanical part pre-project.

\begin{tabular}{|c|c|c|c|c|c|c|c|c|}
\hline \multicolumn{9}{|c|}{ Pregroject in mutrix format } \\
\hline & 1 & 2 & 3 & 4 & 5 & 6 & 7 & 8 \\
\hline PHo0 & $\Delta \mathrm{d}_{1}$ & & $\Delta_{2}$ & & & 노. & & $\Delta \mathrm{dy}_{1}$ \\
\hline PH100 & $\mathrm{N}_{1}$ & & & & $\Delta l_{3}$ & & & \\
\hline PILOOO & & & & slli & $\Delta \mathbf{N}_{\mathrm{s}}$ & & & \\
\hline Fио00 & & $\Delta \mathbf{N}_{2}$ & & & $\Delta d^{\prime \prime}$ & & & \\
\hline FH:00 & & & & & $\Delta^{*{ }^{\prime \prime}}$ & & Ll, & \\
\hline \multicolumn{9}{|c|}{ 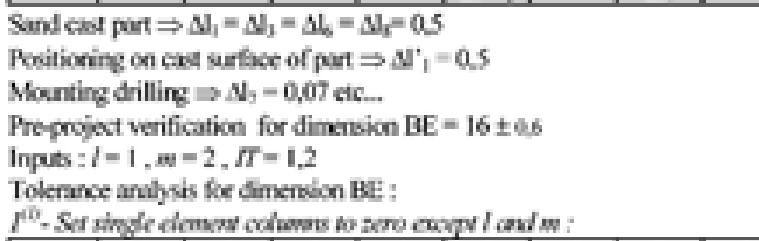 } \\
\hline & 1 & 2 & 3 & 4 & 5 & 6 & 7 & 8 \\
\hline PHOO & $\Delta \mathrm{dl}_{1}$ & & 0 & & & 0 & & 0 \\
\hline FHIO00 & $\mathrm{NV}_{1}$ & & & & $\Delta l_{6}$ & & & \\
\hline FHבOO & & & & 0 & $\mathrm{~N}_{\mathrm{s}}$ & & & \\
\hline PH300 & & $\Delta \mathbf{b}_{2}$ & & & $\Delta{ }^{\prime}{ }_{5}$ & & & \\
\hline FH:00 & & & & & $\Delta J^{m+1}$ & & 0 & \\
\hline \multicolumn{9}{|c|}{ 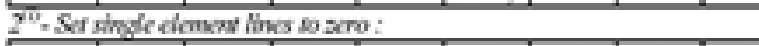 } \\
\hline & 1 & 2 & 3 & 4 & 5 & 6 & 7 & 8 \\
\hline PHOO & 0 & & & & & & & \\
\hline PHIOÓO & $\mathbb{N}_{1}$ & & & & Als & & & \\
\hline FHבOO & & & & & 0 & & & \\
\hline PHBO0 & & $\Delta \mathrm{l}$ & & & $\Delta \|^{\prime \prime}$ & & & \\
\hline PWto0 & & & & & 0 & & & \\
\hline \multicolumn{9}{|c|}{ 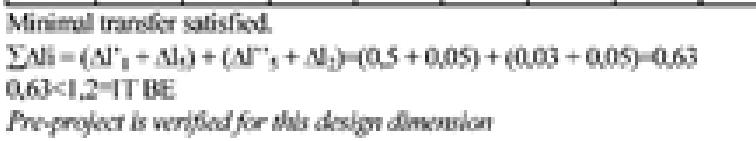 } \\
\hline
\end{tabular}

Figure 3. Verißcation example of dimension $B E=16+0,6$.

only one dispersion $\mathrm{DI}$ are eliminated because a phase needs at least two dispersions $\mathrm{Dl}$, one for the machined surface and another for the positioning surface. This elimination process is carried out until the minimal transfer condition is satis@ed, which is the presence of zero Dl or two Dl per column, except for surfaces that are limits to the design dimension (BE). At the end, we verify equation (2) by summing all the remaining $\mathrm{Dl}_{i}$ dispersions in the matrix.

In the case when equation (2) is not satis®ed, the pre-project is not veri®ed. The tolerance transfer is impossible. This problem can be solved in three ways. The @ist solution consists of changing the tolerance interval IT for the design functional dimension (BE). This decision is the responsibility of the design of ${ }^{\circledR}$ ce. The second one involves changing datum elements and reference planes, which means changing the rooting and operations sheets of the whole process plan. This solution means rewriting a new process plan pre-project. The third solution is more adequate and consists of diminishing the IT of one or more manufacturing dimensions (CF) in the tolerance chain that makes up the IT of the design dimension as given by 


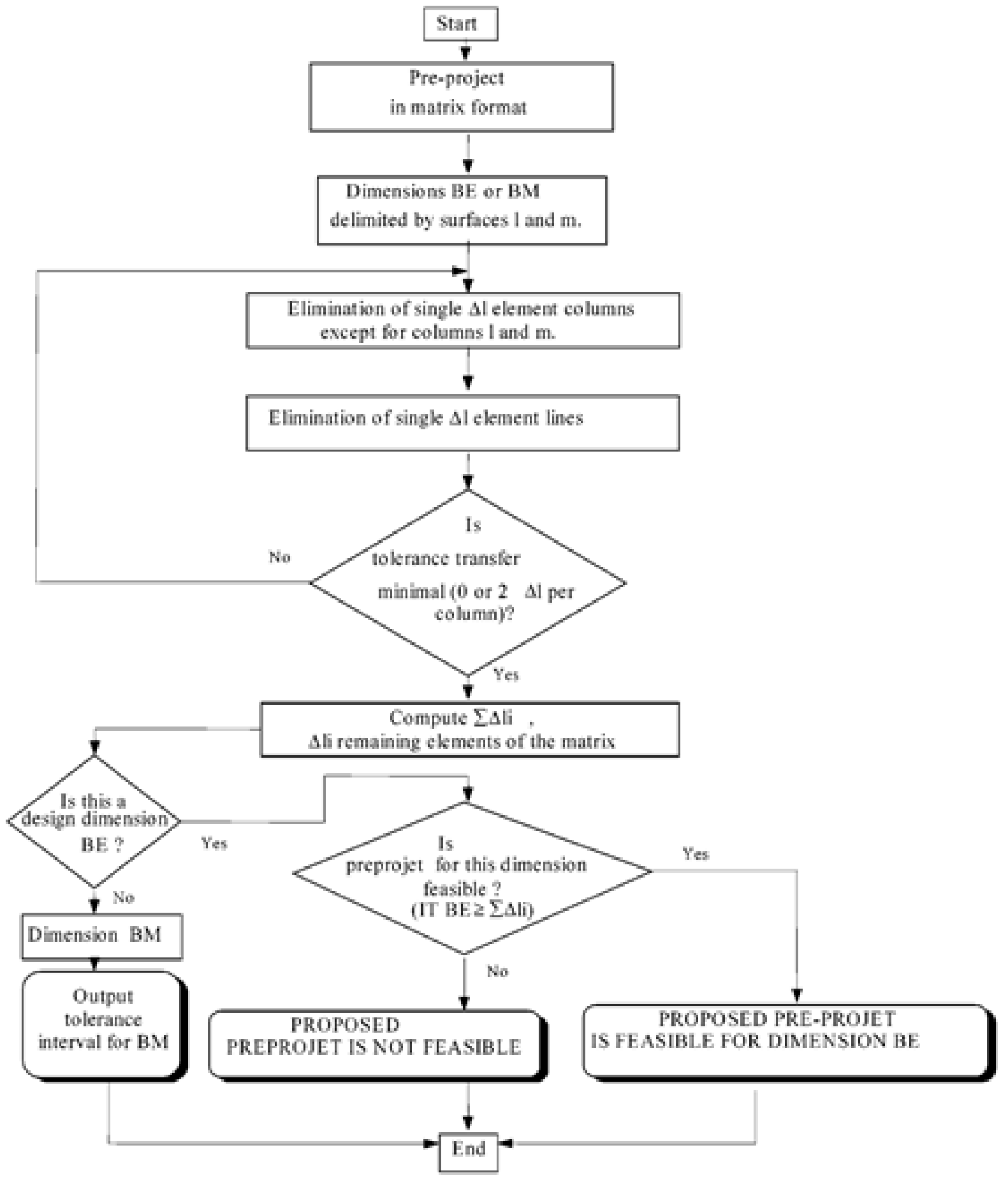

Figure 4. Flowchart of the verißcation procedure.

equation (2). Based on minimal reference dispersions for different processes, which are usually given by experience (Hamou 1998), this solution is based on a successive diminution of the dispersions $\mathrm{Dl}_{\mathrm{i}}\left(\mathrm{DB}_{\mathrm{i}}\right.$ for raw material dispersions) without going under any known minimal reference value.

\subsection{Procedure for the optimization of dispersions}

2.3.1. Optimization based on the minimal dispersions. Once the pre-project has been verißed and retained, the manufacturing tolerance intervals can be computed. To do this, we build an optimization matrix $\mathrm{B}\left(\mathrm{I}_{\mathrm{c}}\right.$, 
$I_{d}$ ) of $p$ lines and $q$ columns where $p$ represents the number of design dimensions and manufacturing dimensions and $q$ the number of dispersions. The ®rst table of @gure 5 contains this matrix (column 3 to column 12) corresponding to the mechanical part of 囚gure 2. Each column represents a dispersion Dl which is affected by a surface beginning with the ${ }^{\circledR}$ rst one, the second one and so on. Then we compute the residuals $\epsilon$ given by the following equation:

$$
\text { e }<\text { IT -dimension BEf } \ddot{\mathbf{y}}^{\mathbf{X}} \mathrm{Dl}_{\mathrm{i}}: \quad-3 f
$$

After the initial distribution matrix has been built and the residuals e computed, we determine the processing order of the lines in this matrix depending on the values of these residuals. This order is given by the increasing values of the residuals. As explained in (B) gure 5, this optimization process consists of an equal

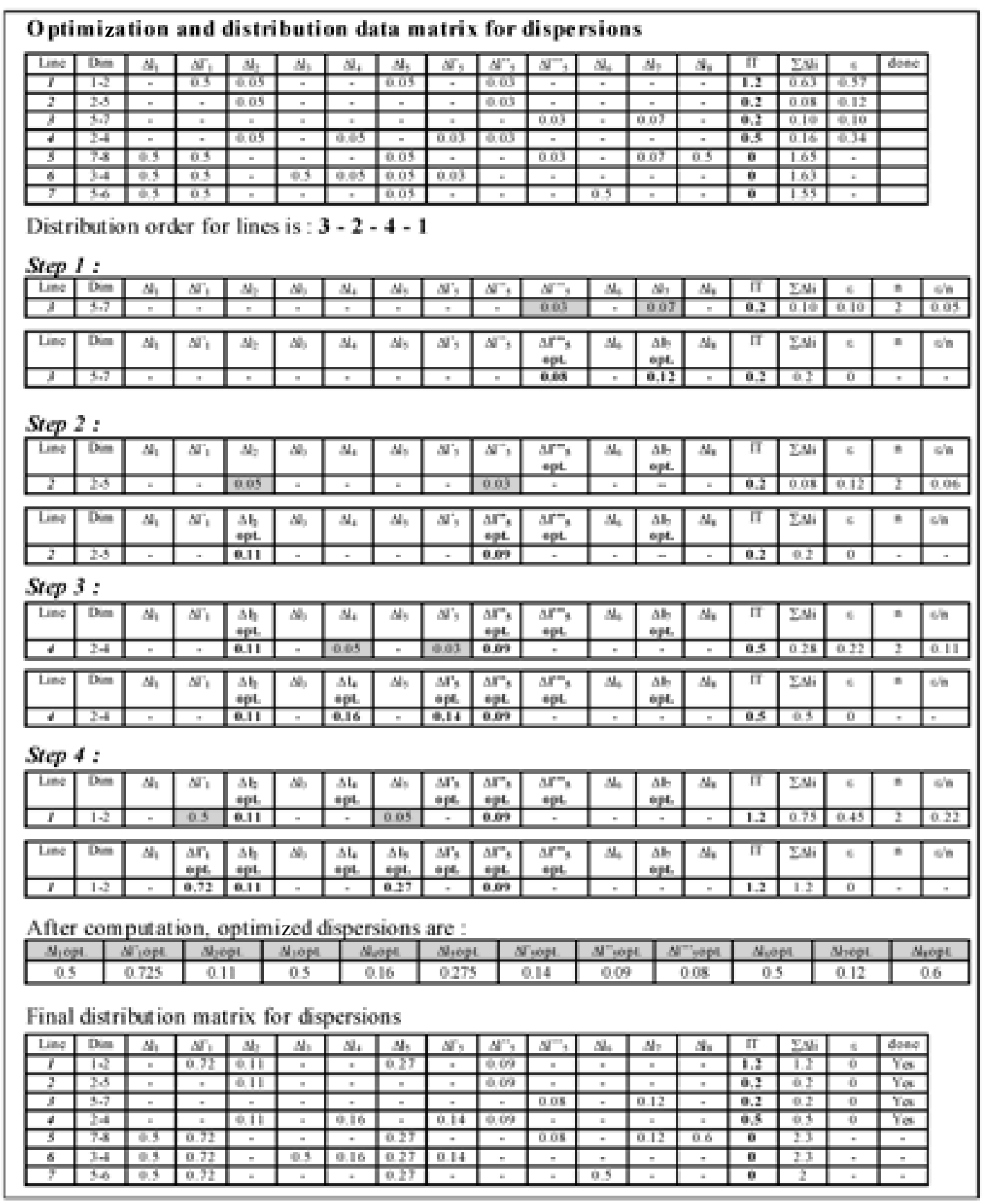

Figure 5. Classical optimization procedure for the sample example. 
distribution of each residual e on the dispersion elements Dl of each line in the matrix so that the following equation is satis®ed:

$$
\text { IT -dimension } \mathrm{BE} f<{ }^{\mathbf{X}} \mathrm{Dl}_{\mathrm{i}} \text { : }
$$

After processing a line, the optimized elements of the matrix are saved and their values are memorized before going to the next line. The tolerance intervals are updated during this process using the optimized dispersions from the previously processed ones. Figure 5 gives the optimization results for the sample example of Rgure 2.

2.3.2. Optimization based on unknown dispersions. A modi@ed form of the dispersions method (Marty

\begin{tabular}{|c|c|c|c|c|c|c|c|c|c|c|c|c|c|c|}
\hline \multicolumn{15}{|c|}{ Dispersions data matrix for simultaneous optimization and verification } \\
\hline Le & $6=$ & A4 & $\overline{N^{\prime}}$ & $a_{0}$ & $N_{4}$ & 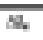 & M, & $\bar{N}$, & $\mathbb{N}^{*}$ & $N^{m,}$ & 4 & M. & Sth & $10 \mathrm{sm}$ \\
\hline$t$ & 12 & 6 & $x_{0}$ & $x y$ & $\%$ & 6 & $x_{3}$ & 6 & 5 & 6 & 6 & 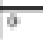 & 6 & 12 \\
\hline 2 & 35 & 6 & 6 & $x$ & 5 & 9 & $\bar{a}$ & 6 & $\sqrt{73}$ & 5 & 8 & $\bar{a}$ & 6 & 25 \\
\hline$y$ & 89 & 7 & 8 & 0 & $\%$ & 6 & $\overline{0}$ & 6 & $\overline{6}$ & $T^{\prime \prime \prime}$ & 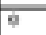 & 5 & 6 & 2.2 \\
\hline 8 & 24 & 6 & 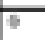 & $\pi$ & 9 & Is & 9 & $\bar{r}$ & 7 & 9 & $\theta$ & 9 & 0 & QS \\
\hline 5 & 74 & $x_{y}$ & $x_{i}$ & 0 & 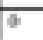 & 0 & $x y$ & 6 & 0 & $x^{\prime \prime \prime}$ & 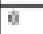 & $x-$ & 5 & $=$ \\
\hline 6 & $\overline{7}$ & $x_{i}$ & $x_{0}$ & 0 & $x_{j}$ & $\overline{F_{i}}$ & I) & $r$ & 6 & 8 & 8 & 9 & 6 & $=$ \\
\hline$y$ & $\Leftrightarrow$ & $x$ & $x_{1}$ & 6 & 9 & 6 & $x$ & 6 & 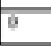 & 9 & $x_{s}$ & के & 6 & $=$ \\
\hline
\end{tabular}

\section{Distribution order for lines is : 2-3-4-1}

Seq $\mathrm{I}$ ?

\begin{tabular}{|c|c|c|c|c|c|c|c|c|c|c|c|c|c|c|}
\hline Les & $\sigma=$ & is & $W_{1}$ & in & $\Delta_{1}$ & 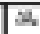 & at. & $\mathscr{H}$, & 24 & $\Delta^{\prime \prime \prime}$, & 고 & 2 & $\Delta$ & $\pi_{\mathrm{Cm}}$ \\
\hline 2 & 25 & 6 & 5 & $x_{z}$ & 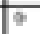 & 6 & 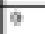 & 6 & 5 & 9 & 6 & 9 & 6 & 0,2 \\
\hline
\end{tabular}

\begin{tabular}{|c|c|c|c|c|c|c|c|c|c|c|c|c|c|c|c|}
\hline Lex & $D=$ & म4 & $S^{\prime}$, & 山is & 2 & 2 & 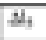 & si, & $2^{2}$ & $a^{\prime \prime \prime}$, & II & 4 & 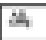 & $11 \mathrm{Cm}$ & $\pi_{f}$ \\
\hline$\sqrt{2}$ & 25 & 6 & 6 & 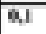 & $\%$ & 6 & 5 & 6 & 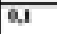 & 5 & 6 & 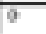 & 6 & 0.2 & 2 \\
\hline
\end{tabular}

$\operatorname{Sic} 27$

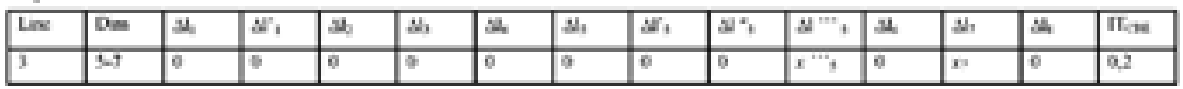

\begin{tabular}{|c|c|c|c|c|c|c|c|c|c|c|c|c|c|c|c|}
\hline LE & $D=$ & 프 & $\Delta$ & 幽 & $\Delta$, & sh & $\Delta$, & $\Delta$, & $s^{*}$ & 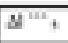 & 프 & $y_{1}$ & $\Delta$ & $\pi \mathrm{rm}$ & $x$ \\
\hline$\sqrt{3}$ & $3-7$ & 9 & 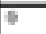 & $\theta$ & $\%$ & 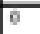 & 9 & 8 & 0 & 21 & $\theta$ & 81 & 6 & 0,2 & 0,1 \\
\hline
\end{tabular}

\section{Sing 3}

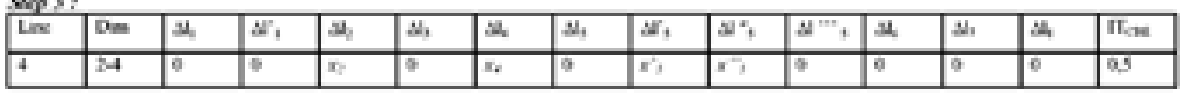

\begin{tabular}{|c|c|c|c|c|c|c|c|c|c|c|c|c|c|c|c|}
\hline Les & $0 \mathrm{~m}$ & ix & $W^{\prime}$, & ind & $\Delta$, & 2 & ㄴ, & $\mathscr{H}$, & 24 & $s^{\prime \prime \prime}$, & 그 & עy & 4 & $\pi \mathrm{rm}$ & k \\
\hline 4 & 24 & 8 & \% & 0,1 & 8 & 0.15 & 9 & 0,15 & 0,1 & 8 & 6 & 9 & 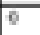 & 05 & 0,15 \\
\hline \multicolumn{16}{|c|}{ Sept: } \\
\hline LEx & $D=$ & 느. & $\Delta$ & is & $\Delta$ & ses. & $\Delta$ & $\Delta$, & s' & $\Delta^{m+}$, & sis & 31 & $\Delta$ & $\pi \mathrm{TH}$ & \\
\hline 1 & $1-2$ & 6 & $x^{2}$ & $x_{7}$ & 9 & 0 & $x y$ & 0 & $=7$ & 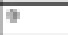 & 6 & 0 & ${ }^{\circ}$ & 1,2 & \\
\hline Le & $\mathrm{ne}$ & & & & & & & & & & & & & & \\
\hline in & . & $\infty$ & Ni, & s) & Wis & s. & N & N, & $\alpha^{2}$ & $\Delta+$ & st & Nis & sh & U:m & 2 \\
\hline 1 & $1-2$ & $\theta$ & 43 & 0,1 & o & 0 & 23 & 6 & 0.1 & 0 & 0 & 0 & 6 & 1.2 & 63 \\
\hline
\end{tabular}

After computation , optimized dispersions are :

\begin{tabular}{|c|c|c|c|c|c|c|c|c|c|c|c|}
\hline$\Delta_{1} \Delta$ & $M^{\prime}, \mathrm{n}$ & $\vec{u}_{1}+$ & - & $\mathbb{3}_{i=}=$ & sher & $\Delta r_{1},-$ & SIn & 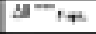 & $34=$ & - D. & $3 \mu_{4}+$ \\
\hline 63 & 85 & 01 & 05 & Q.B & 6.5 & 6,13 & 6,1 & 4 & $\sqrt{3}$ & का & 05 \\
\hline
\end{tabular}

Final distribution matrix for dispersions

\begin{tabular}{|c|c|c|c|c|c|c|c|c|c|c|c|c|c|c|}
\hline Lew & $6=$ & s, & $N_{i}$ & $\Delta_{0}$ & $N_{4}$ & A, & $A_{4}$ & $w_{i}$ & $\Delta$, & $N^{\prime \prime}$, & sa & $N_{1}$ & $\Delta \omega_{4}$ & $\pi / \mathrm{mon}$ \\
\hline t & 12 & 6 & 83 & at & $\%$ & 6 & 25 & 6 & 80 & P & 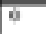 & 0 & 6 & 12 \\
\hline$z$ & 25 & 6 & D & 0,1 & 9 & 6 & 9 & 0 & 0.1 & 9 & $\theta$ & 0 & 0 & 0.2 \\
\hline 5 & 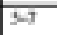 & 6 & $\%$ & 0 & 9 & 0 & 9 & 6 & 9 & का & 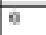 & 0,1 & 8 & 0.2 \\
\hline 7 & 24 & 6 & 5 & 0,1 & 5 & 0 & 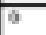 & $\sqrt{0,13}$ & 0,1 & 5 & 6 & 5 & 6 & 0.5 \\
\hline$\sqrt{3}$ & $\begin{array}{ll}74 \\
\end{array}$ & 20 & 63 & 6 & 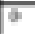 & 6 & 25 & 6 & 6 & का & 6 & का & 3 & $=$ \\
\hline 8 & $\sqrt{34}$ & 25 & 83 & 6 & 63 & 2.15 & 25 & 2.15 & 5 & ? & 6 & 9 & 6 & $=$ \\
\hline 7 & 4 & 65 & 23 & $\%$ & 6 & $\%$ & as & $\%$ & 9 & 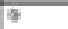 & 25 & 9 & 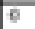 & $=$ \\
\hline
\end{tabular}

Figure 6. Modi®ed optimization procedure for the sample example. 
and Linares 1994) is used in combination with the minimal transfer method to build the dispersions data matrix for the simultaneous veri®cation and optimization procedure. However, since no reference values are used, each dispersion participating in the tolerance chain for the design and manufacturing dimensions is given the letter $x$ as a value. Others are given the value zero in the starting data matrix as highlighted by the ${ }^{B}$ rst table of ${ }^{\circledR}$ gure 6 . Then, we compute the distribution coef®cient $k$ for each design dimension $B E$ using equation (5). The increasing values of this coef@cient give the processing order for the tolerance distribution. It is noticed that for the ${ }^{\circledR} \mathrm{rst}$ iteration $\mathrm{k}$ equals the $\mathrm{BE}$ tolerance value. Following this order, each line is processed by distributing the design tolerance value among the participating dispersions and their values are saved in the distribution matrix, as explained in @gure 6 for the example of @gure 2. In opposition to the minimal dispersions method, where a complete distribution of the residuals is not guaranteed, the unknown dispersions method always distributes the full tolerance values among the unknown dispersions.

$$
\mathrm{k}_{\mathrm{j}}<\frac{\mathrm{IT} \mathrm{T}_{\mathrm{CBE}} \ddot{\mathbf{Y}}_{\mathrm{i}}^{\mathbf{P}_{\mathrm{m}} \mathrm{Dli}}}{\mathrm{p}}
$$

where

$\mathrm{IT}_{\mathrm{CBE}}$ is the tolerance interval for design dimension (BE),

$\mathrm{m}$ is the number of known dispersions,

$p$ is the number of unknown dispersions,

$j$ is the iteration order.

\subsection{Procedure for computing manufacturing dimensions}

In the veri®cation procedure of the design dimensions, and when the condition of minimum transfer is satis@ed, the manufacturing dimensions participating in the design dimensions are those bounded by surfaces having the two dispersions stationed on the same stage. Thus, we obtain all the manufacturing dimensions in the pre-project. Based on the fundamental model developed by Bourdet (1975) and on the matrix of the pre-project, we can calculate an average length $\mathrm{I}_{\mathrm{i}}$ limited by two $\mathrm{Dl}_{\mathrm{i}}$. For each phase, the origin of basic average lengths is taken on the leftmost surface (surface $1, l_{1}=0$ ). Using the design dimensions (BE) and the manufacturing dimensions (BM) we build a system of equations to determine the basic average lengths $I_{i}$ using relations (6) and (7) as follows:

$$
\begin{aligned}
& C f_{i \ddot{j} j \text { ave: }}<\mathrm{I}_{\mathrm{j}} \ddot{\mathbf{y}} \mathrm{I}_{\mathrm{i}} ; \\
& \mathrm{Cpm}_{\mathrm{i} \ddot{\mathrm{y} j} \text { ave: }}<\mathrm{I}_{\mathrm{j}} \ddot{\mathrm{y}} \mathrm{I}_{\mathrm{i}} ;
\end{aligned}
$$

where

$\mathrm{Cf}_{\mathrm{i}-\mathrm{j} \text { ave. }}$ is the average design dimension (BE), (BM).

$\mathrm{Cpm}_{\mathrm{i}-\mathrm{j}}$ ave. is the average minimal stock removal

Figure 7 explains this procedure for the example of ® ${ }^{\circ}$ gure 2. This ${ }^{\circledR}$ gure highlights the system of 12 linear algebraic equations obtained using the data of the preproject. After the solution of the system of equations, the computed values of the average lengths $I_{i}$ for the eight surfaces are used to calculate the average manufacturing dimensions $\mathrm{CF}_{\mathrm{i}-\mathrm{j}}$ ave. The tolerance interval IT is then computed for each dimension $\mathrm{CF}_{\mathrm{i}-\mathrm{j}}$ using the previously optimized dispersions $\mathrm{Dl}_{i}$ on each surface $\mathbf{i}$ delimiting the dimension. Figure 7 shows that

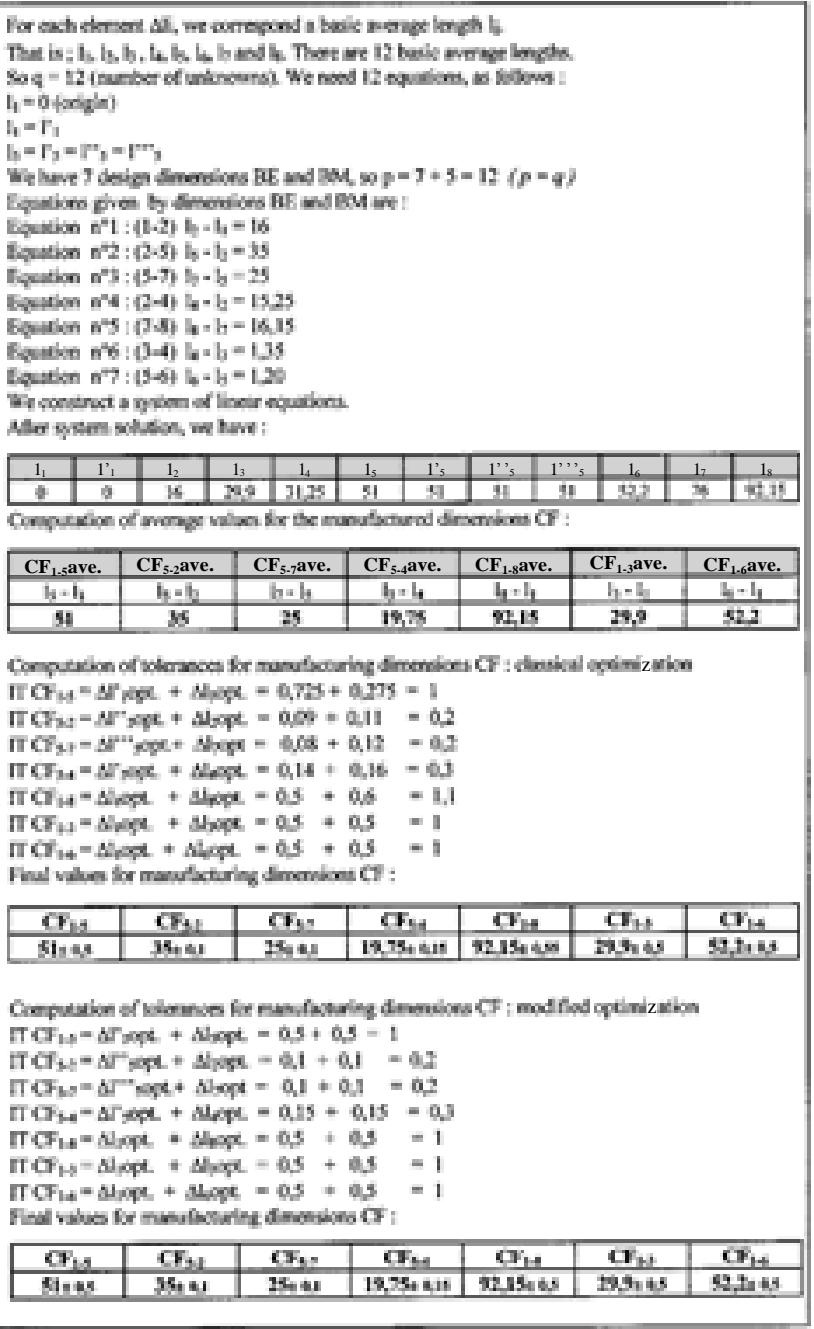

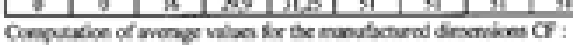

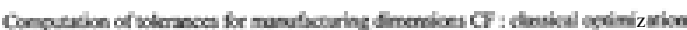

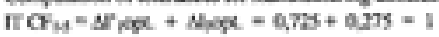

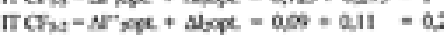

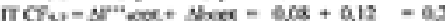

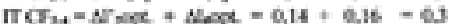

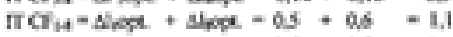

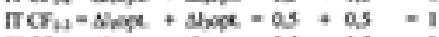

\begin{tabular}{|c|c|c|c|c|c|c|}
\hline Crs & $\mathrm{CF}_{\mathrm{AL}}$ & $F_{31}$ & $\mathrm{CF}:$ & $\mathrm{CF}_{\mathrm{n}}$ & $C_{H}$ & $\mathrm{Cr}_{14}$ \\
\hline Stinat & $35+4$ & 25,4 & 12,75, and & 72.15400 & Exhes & $50,5,0$. \\
\hline \multicolumn{7}{|c|}{ 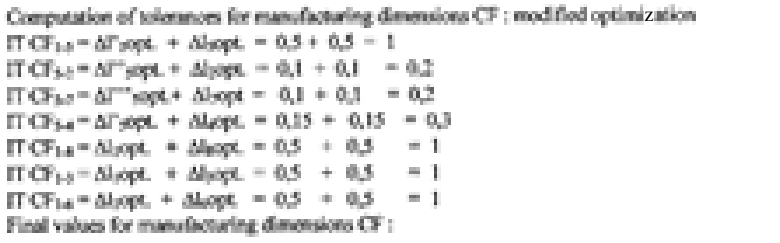 } \\
\hline C.s. & $\mathrm{Cr}_{21}$ & $\mathrm{CF}_{3}$ & $\mathrm{CF}_{\mathrm{H}}$ & $\mathrm{CY}_{1}$ & $\mathbf{C Y}_{\mathrm{n}}$ & $\mathrm{CP}_{1 \mathrm{t}}$ \\
\hline Sinses & $35+21$ & 2501 & $12,75,2.15$ & $x 2.15405$ & Dancs & S2,tans \\
\hline
\end{tabular}

$\mathrm{rCF}_{14}=$ Alopt + Alapt $=$ os + as -

Find vilue for mavulatiaring fimeniont CV :

Figure 7. Computation of manufacturing dimensions for the sample example. 


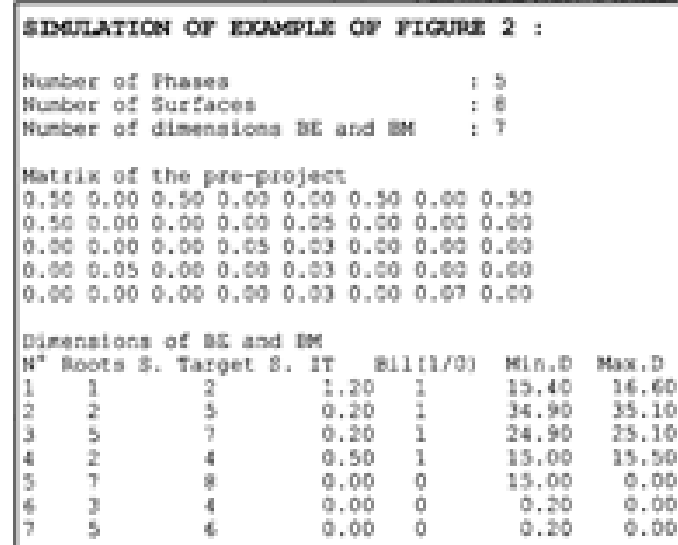

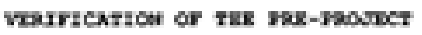

Cosputaries of EAls of design dimensios 2 betweet surfaces $\mathrm{j}-1$ and $m=2$ :

The matix atter eliesnation of coluans having ofo elerent except 1 asd on

$0.500 .006,000,000.000 .000,000.00$

$0,50.000 .000 .000 .050 .050 .050 .00$

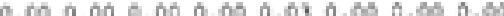

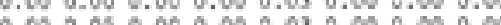

$0.650 .00 \quad 0.00 \quad 0.00 \quad 0.03 \quad 0.00 \quad 0.00 \quad 0.00$

The matrix after o:irination of lines having ote eleaent:

$0.00 \quad 0.000 .000 .050 .000 .000 .000 .00$

0.500 .000 .060 .650 .050 .650 .050 .00

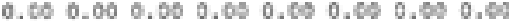

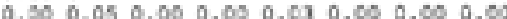

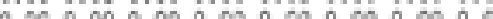

sone $[: 1=0.63$ r7 $[1]=1.20$ Residual $[1]=0.5 \%$

\section{Frempeject in verified for design dimensien a}

Coeputaties of YAli of design dimensios 2 betwee? sut

The natrix after elinination of polunns havieg ote

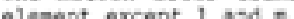

0.590 .000 .000 .050 .050 .050 .090 .09

a.s 0.000 .000 .000 .050 .000 .000 .09

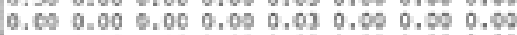

$0.00 \quad 0.05 \quad 0.00 \quad 0,090.030 .00 \quad 0,000.00$

$0,000.000 .000 .050 .030 .060 .060 .06$

the matrix after elindastion of lines having one element:

$0.050 .00 \quad 0,000,000,000,000.00 \quad 0.02$

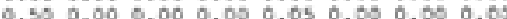

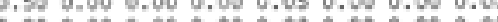

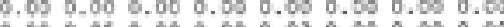

D.05 0.05 .

$0.050 .00 \quad 0.000 .050 .050 .050 .000 .00$

The matrix after elinination of colunn having ond elewent except 1 and $x$ :

$0.00 \quad 0.00 \quad 0.00 \quad 0.050 .000 .050 .000 .00$

0.650 .000 .060 .050 .050 .050 .000 .00

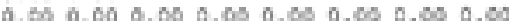

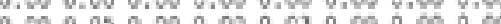

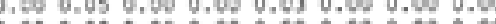

The matix atter elisifation of lines having one elesent:

$0.00 \quad 0.000,000.090 .000 .000 .000 .00$

$0.00 \quad 0.00 \quad 0.00 \quad 0.050 .060 .00 \quad 0.00 \quad 0.60$

$0.000 .00 \quad 0.000 .050 .000 .060 .000 .00$

$0.000 .050 .000 .050 .030,000.000 .00$

$0, \infty 0,00,0,00,0,00,0,00,0, \infty 0,0,000,00$

sus[2]-0, on $17[2]-0.20$ Mnasosal $(2)=0.22$

Fre-preject in verified for deaige dimanion 2

Conputatich of $\mathrm{EAI}$ of design dinensios 3 betwees surfaces $\mathrm{I}=\mathrm{S}$ and $\mathrm{se}$ ?

the natrix after tininatios of coluns having ore eleacent except 1 gad a
0.50 .0 .000 .000 .000 .000 .000 .000 .05 $0.500 .00 \quad 0.000 .00 \quad 0.05 \quad 0.000 .000 .05$ $0.00 \quad 0.00 \quad 0.00 \quad 0.00 \quad 0.03 \quad 0.00 \quad 0.00 \quad 0.09$ $0.00 \quad 0.00 \quad 0.00 \quad 0.00 \quad 9.03 \quad 0.00 \quad 9.00 \quad 0.09$ 0.900 .000 .000 .000 .030 .000 .070 .00

The natrix after elindatios of lifes baving ose elesert:

$0.00 \quad 0,000,000,000,00 \quad 0,000,000,00$ $0.500 .00 \quad 8.000 .000 .050 .000 .000 .05$ $0.000 .00 \quad 8.000 .00 \quad 0.000 .000 .000 .05$ $0.00 \quad 0.00 \quad 0.00 \quad 0.00 \quad 0.008,000.000,00$ $0.00 \quad 0,00 \quad 0,00 \quad 0,00 \quad 0,03 \quad 9,00 \quad 9,07 \quad 0,00$

The satrix after elisinatien of colunes havisg ose elenest encept 1 ans in 1

$0.90 \quad 0.00 \quad 0.00 \quad 0.000 .000 .000 .000 .00$ $0.00 \quad 0.00 \quad 0.00 \quad 0.00 \quad 0.05 \quad 0.00 \quad 0.00 \quad 0.00$ $0.005 .00 \quad 0.000 .000 .000 .000 .000 .00$ $0.003 .00 \quad 0.000 .00 \quad 0.000 .000 .090 .00$ 0.600 .000 .000 .000 .030 .000 .070 .00

The astix after eliainasion of lites having one element:

$0.60 \quad 0.00 \quad 0.00 \quad 0.00 \quad 0.00 \quad 9.00 \quad 0.000,00$ $0.500 .00 \quad 0.000,000.009 .000 .000 .00$ $0.60 \quad 0.00 \quad 0.00 \quad 0.00 \quad 0.00 \quad 0.00 \quad 0.00 \quad 0.00$ $0.000 .00 \quad 0.000 .000 .000 .000 .00 \quad 0.00$ $0.600 .00 \quad 0.00 \quad 0.00 \quad 0.030 .00 \quad 0.070 .00$ Sua $[3]=0,10 \mathrm{Iz}(3)]=0,20$ Residea: $[3]=0,10$

Pre-prejeot is rerified for denign dimenaica 3

Coaputatios of EAIL of design dimension 4 between burtaces $2=2$ and $2=4$ =

The natix after elinisatios of colums havim one elenent except 1 and $=$ :

$0.50 \quad 0.00 \quad 0,000.000,000,000,000,00$

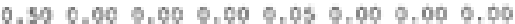

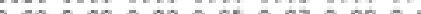

.

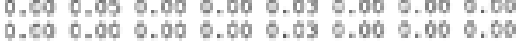

fhe satrix after tilsinstion of lises having ose elevent :

$0.00 \quad 0.000 .000 .000 .000 .000 .000 .00$

$0.50 \quad 0.00 \quad 0.00 \quad 0.00 \quad 0.058 .00 \quad 0.00 \quad 0.00$

$0.600 .00 \quad 0.000 .050 .030 .000 .000 .00$

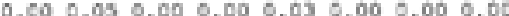

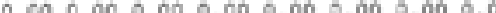

The hatrix after elisisatice of colunes havim one element except 1 and $\mathrm{m}$ !

$0.60 \quad 0.00 \quad 0.00 \quad 0.000 .000 .000 .000 .00$

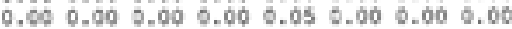

$0.00 \quad 0.00 \quad 9.00 \quad 0.05 \quad 0.03 \quad 5.00 \quad 0.00 \% .00$

$0.00 \quad 0.05 \quad 0.00 \quad 5.00 \quad 0.03 \quad 0.00 \quad 0.00 \quad 0.00$

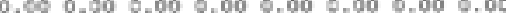

The ratrix after elinination of lifes havisg ose elenent:

$0.00 \quad 0.00 \quad 0.00 \quad 0.00 \quad 0.00 \quad 0.00 \quad 0.00 \quad 0.00$

$0.600 .00 \quad 5.00 \quad 0.00 \$ .00 \$ .00 \$ .009 .00$

$0.00 \quad 0.00 \quad 0.00 \quad 0.050 .03 \quad 0.00 \quad 9.00 \quad 0.00$

$0.60 \quad 0.05 \quad 0.00 \quad 0.00 \quad 0.03 \quad 9.00 \quad 0.00 \quad 0.00$

$0 . c 0 \quad 0.00 \quad 0.000 .00 \quad 0.000 .000 .000 .00$

Sua $[t]=0.16 \quad 17 i 4]=0.50$ Residat $(4)=0.34$

Pre-preject in verified for design dinesien 4

Coaputatios of ENi of design dieension 5 between corfaces $1-7$ and $\mathrm{n}-\mathrm{B}$ :

Tte natrix after oliniratioe of colunh havitg ose element axcaps 1 and $=$.

$0.500 .00 \quad 0.000 .00 \quad 0.00 \% .00 \quad 0.000 .50$

$0.50 \quad 0.00 \quad 0.00 \quad 0.000 .05 \quad 0.000 .000 .00$

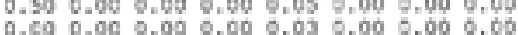

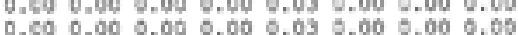

$0.000 .00 \quad 0.00 \quad 0.00 \quad 0.09 \quad 0.00 \quad 0.07 \quad 9.00$

The natfix ofter eilnination of lines havisg ote element:

$0.50 \quad 0.000 .000 .000 .00 \quad 0.00 \quad 0.00 \quad 0.50$

$0.50 \quad 0.00 \quad 0.00 \quad 0.00 \quad 0.05 \quad 0.000 .00 \quad 0.00$

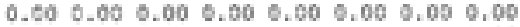

$0.00 \quad 0.00 \quad 0.00 \quad 0.00 \quad 0.00 \quad 0.00 \quad 0.000 .00$

$0.005 .000 .000 .000 .030,000,070,00$ 


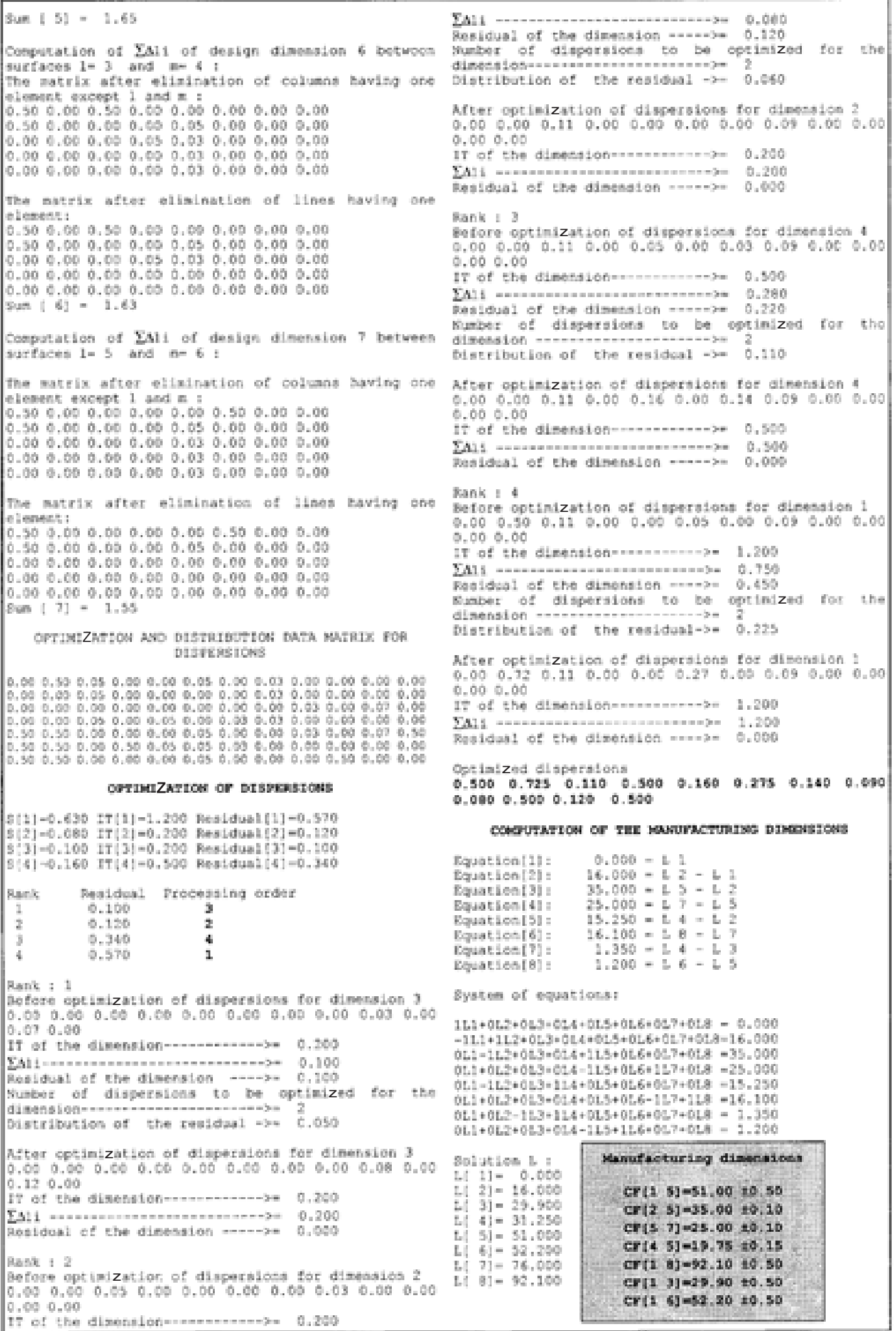

Figure 8. Results of the automated simulation for the sample example. 
the ${ }^{\circ}$ nal tolerance values given by the modi®ed dispersions optimization method for the simple example are similar to the results given by the classical dispersions optimization method. However, in reality, the former always gives better results than the latter, as was verißed with more complex examples. Furthermore, the modi@ed dispersions method overcomes the problem of unknown minimal reference dispersions that are not always available in the industrial literature or are difßcult to assess from experience.

\section{Programming and validation tests for the simulation}

The procedures forming the simulation have been integrated in one module and programmed in order to be tested. The ${ }^{\circledR}$ nal computer program consists of $® v e$ functions. The @rst function permits the input and preparation of the pre-project data in matrix format. The second function performs the pre-project veri®cation and eventual solution of impossible tolerance transfer. The third function executes the optimization procedure of dispersions. The fourth function computes the manufacturing dimensions. The $₫$ fth function computes the setting dimensions. The program is validated by practical and complex process plan simulations and is compared to classical manual simulations (Hamou 1998). Figure 8 gives an overview of the output results of the developed module for the pre-project sample of @gure 2. This software, which is designed as a standalone module, can be easily integrated in a CAPP system or a more general CAD/ CAM system. The program can extract its initial preproject data from the upstream CAPP modules. On the other side, it can communicate its simulation results to the downstream departments of manufacturing, such as numerical control processing activities.

\section{Conclusions and perspectives}

The objectives set forth by this research work were to automate the process plan simulation activity as a separate module or within a CAPP system. The manufacturing dispersions or capabilities are at the root of the development of a combined programmable methodology, based on the minimal transfer method, the minimal reference dispersions method and a proposed modi@ed dispersions method. It is shown that the modi®ed dispersions method performs a simultaneous veri®cation and optimization without the need of the minimal reference dispersions that are not always available for all processes. On the basis of the developed programmed methodology, a computerised module has been designed in the form of three procedures. The $\circledast$ rst procedure permits the veri®ca. tion of the process plan pre-project. The second procedure permits an optimization of dispersions. The third procedure permits the computation of the optimized manufacturing dimensions and tolerances. The $®$ nal module of simulation has been tested on complex examples. These results have shown that the methodologies used can help process designers in the activity of manufacturing tolerance analysis and distribution within a CAPP system. Further research is undergone on one side, in order to perform a nonequal redistribution of excess tolerance depending on the complexity of the manufacturing dimensions. On the other side, investigations are being conducted for automating the extraction of a manufacturing tolerance chain in order to perform a cost-based statistical optimization of tolerance transfers and distribution on the manufacturing dimensions.

\section{References}

Bourdet, P., 1975, Les chaã̃nes de cotes de fabrication. Revue de I'Ingênieur et du Technicien de L'enseignement Technique, 191, $15 \pm 23$.

Cнегік, A., 1997, Integrating functional tolerancing in computer aided engineering environments. Proceedings of the Second Jordanian International Mechanical Conference, Amman, Jordan, pp. $960 \pm 968$.

Duret, T., 1981, Simulation de gamme d'usinage. Revue de l'Ingênieur et du Technicien de L'enseignement Technique, 229. $34 \pm 37$.

Fainguelernt, D., Weill, R. and Bourdet, P., 1986, Computer aided tolerancing and dimensioning in process planning. Annals of the CIRP, 35(1), $311 \pm 315$.

Graves, S. and BisGaARD, S., 1999, Integrated tolerance management. Proceedings of the Sixth CIRP International Seminar on Computer Aided Tolerancing, Twente, Netherlands, pp. $385 \pm 394$.

Hamou, S., 1998, A module for process plan simulation and tolerance transfer in computer aided manufacturing. Master thesis, ENSET, Oran, Algeria.

Halevi, G. and Weill, R. D., 1995, Principles of Process Planning a Logical Approach (London: Chapman and Hall).

MarTy, C. and Linares, J. M., 1994, Industrialisation des produits mêcaniques: conception et industrialisation (Paris: Hermés, Tome 1).

WeILL, R., Integrating dimensioning and tolerancing in computer aided process planning. Robotics and Computer Integrated manufacturing, 4(1/2), $41 \pm 48$. 